\title{
Erratum: The role of in situ stress in determining hydraulic connectivity in a fractured rock aquifer (Australia)
}

\author{
Luke Mortimer • Adnan Aydin • Craig T. Simmons • \\ Graham Heinson • Andrew J. Love
}

\section{Erratum to: Hydrogeology Journal (2011) \\ DOI 10.1007/s10040-011-0760-z}

The Figure $11 \mathrm{~b}$ presented in the original article was the wrong figure. The correct Figure 11b is presented here.

The caption is the same.

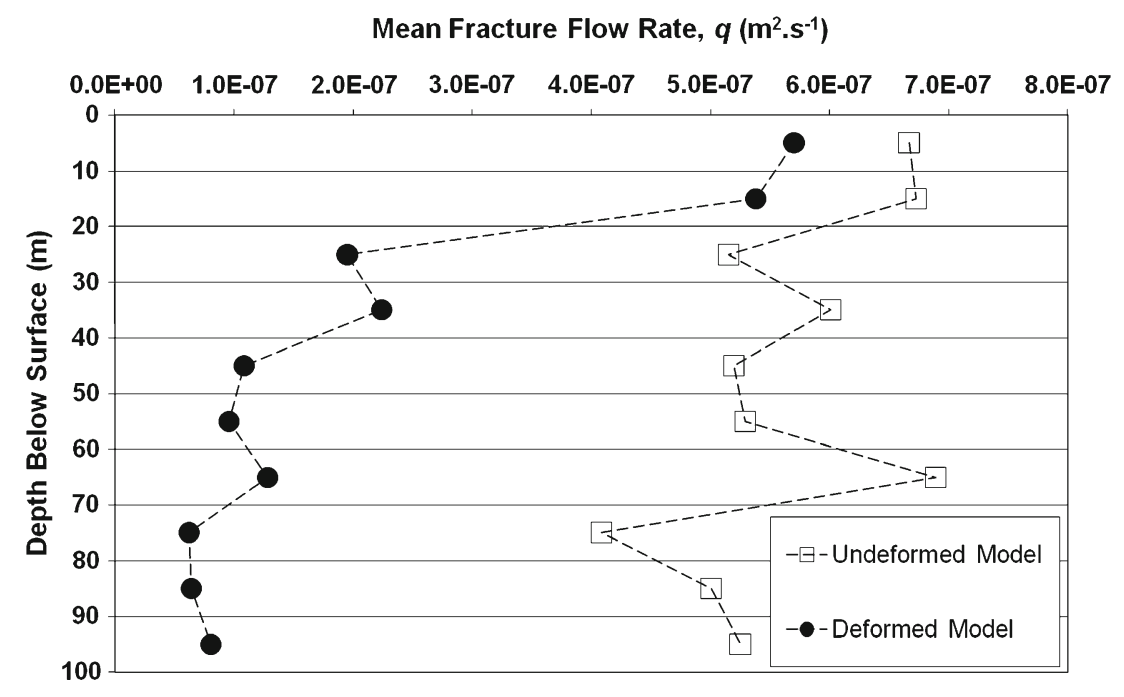

Published online: 18 August 2011

(C) Springer-Verlag 2011

The online version of the original article can be found at http://dx. doi.org/10.1007/s10040-011-0760-z.

L. Mortimer $(\bullet) \cdot$ C. T. Simmons $\cdot$ A. J. Love

School of the Environment and National Centre for Groundwater

Research and Training,

Flinders University,

G.P.O. Box 2100, Adelaide, South Australia 5100, Australia

e-mail: luke.mortimer@flinders.edu.au

Tel.: +61-3-98277740

Fax: +61-8-82015635

A. Aydin

Department of Geology and Geological Engineering,

University of Mississippi,

PO Box 1848, University, MS 38677, USA

G. Heinson

School of Earth and Environmental Sciences,

University of Adelaide,

Adelaide, South Australia 5005, Australia 